\title{
Teaching weight to explicitly address language ambiguities and conceptual difficulties
}

\author{
Rex Taibu \\ Queensborough Community College-City University of New York, Bayside, New York 11364, USA \\ David Schuster \\ Department of Physics \& The Mallinson Institute for Science Education, Western Michigan University, \\ Kalamazoo, Michigan 49008, USA \\ David Rudge \\ Department of Biological Sciences \& The Mallinson Institute for Science Education, \\ Western Michigan University, Kalamazoo, Michigan 49008, USA
}

(Received 1 August 2016; published 1 June 2017)

\begin{abstract}
Language ambiguities in concept meanings can exacerbate student learning difficulties and conceptual understanding of physics concepts. This is especially true for the concept of "weight," which has multiple meanings in both scientific and everyday usage. The term weight has been defined in several different ways, with nuances, but in textbooks and teaching the term is almost always defined in one of two ways: operationally either as the contact force between an object and a measuring scale or as the gravitational force on an object due to some other body such as Earth. The use of the same name for different concepts leads to much confusion, especially in accelerating situations, and to conflicting notions of "weightlessness" in free fall situations. In the present paper, we share an innovative approach that initially avoids the term weight entirely while teaching the physics of each situation, and then teaches the language ambiguities explicitly. We developed an instructional module with this approach and implemented it over two terms in three sections of an introductory physics course for preservice elementary teachers. Learning gains for content understanding were assessed using pretests and post-tests. Participants achieved remarkably high gains for both static and accelerating situations. Surveys pre- and postinstruction showed substantially improved appreciation of language issues and ambiguities associated with weight, weightlessness, and free fall. Interviews with instructors teaching the module provided additional insight into the advantages and teaching demands of the new approach.
\end{abstract}

DOI: 10.1103/PhysRevPhysEducRes.13.010130

\section{INTRODUCTION}

Although the term "weight" is familiar in both everyday life and science, the concept is nevertheless challenging to teach and difficult for students to understand, particularly in the context of nonequilibrium situations involving acceleration. The difficulties, ambiguities, and confusions surrounding weight are partly conceptual, partly language related, ${ }^{1}$ and sometimes a mixture. These problems arise because weight is conceptualized and formally defined in different ways among physicists, across textbooks, and by teachers. This goes well beyond the fact that in everyday discourse weight is often confused with mass.

\footnotetext{
${ }^{1}$ Throughout this paper, the terms "language" and "semantics" will be used interchangeably to refer to the issues surrounding the meanings of terms such as weight.

Published by the American Physical Society under the terms of the Creative Commons Attribution 3.0 License. Further distribution of this work must maintain attribution to the author $(s)$ and the published article's title, journal citation, and DOI.
}

Physicists differ regarding whether the term weight should be used for the contact force between an object and a measuring scale (the operational definition) or for the gravitational force on an object by some other body such as Earth (the gravitational definition). Textbooks adopt one or the other definition, usually without explicit comment or discussion, and teachers do likewise. In static (nonaccelerating) situations, the two conceptually distinct definitions lead to the same value for weight, but in accelerated situations (for example, in an elevator or an orbiting spaceship) the alternative definitions lead to different values for an object's weight. ${ }^{2}$ Such conceptual and terminological ambiguities are problematic not only for the teaching and learning of weight, but also for "apparent weight" and "weightlessness," each of which carries similar ambiguities [1]. The various kinds of equilibrium and accelerating situations commonly treated in textbooks and courses are illustrated in Fig. 1. These are the cases

\footnotetext{
2It should be noted that, aside from this "naming" issue, the physics of the underlying constructs themselves is fairly straightforward as a part of dynamics.
} 


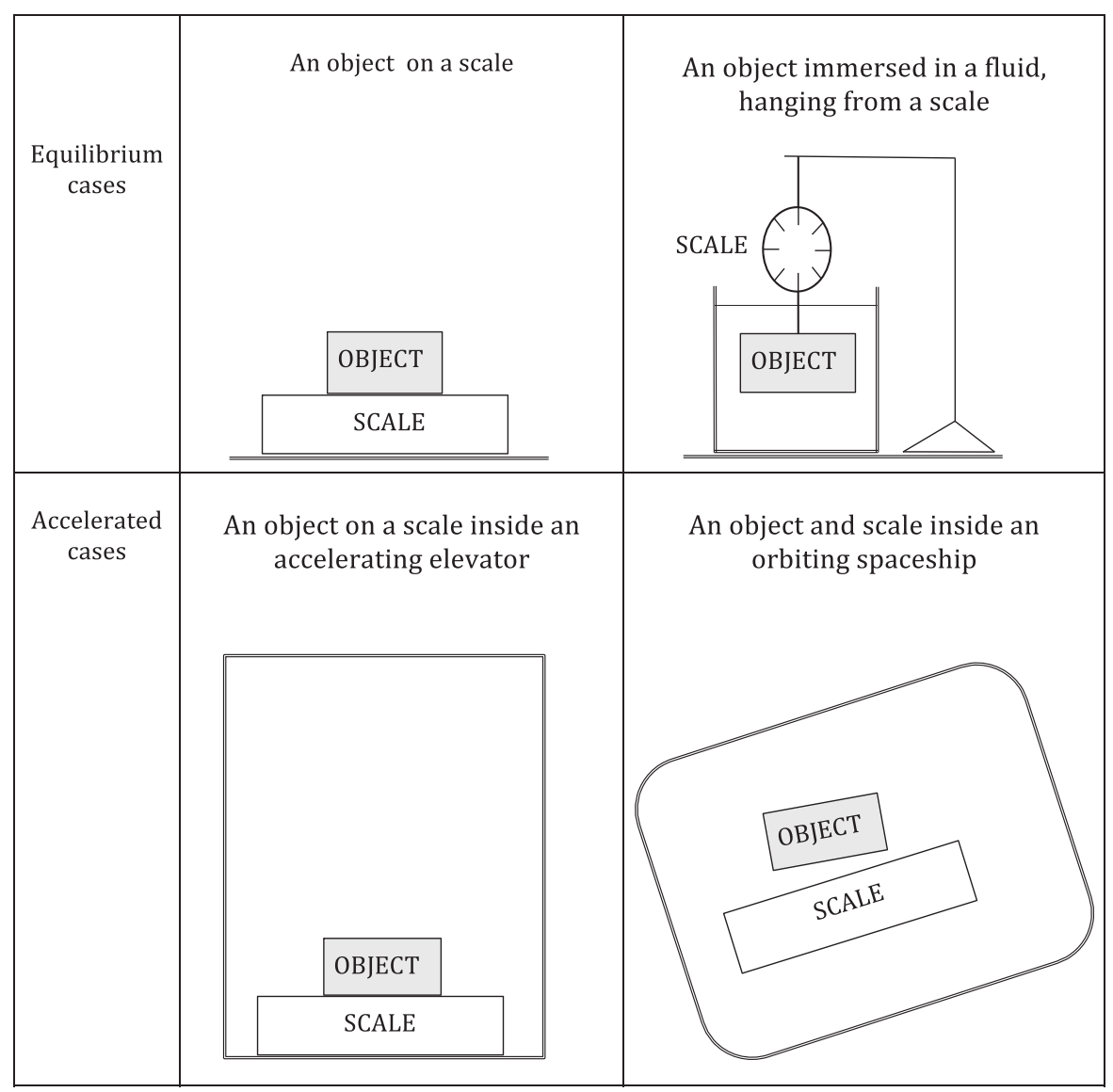

FIG. 1. Various equilibrium and accelerated cases involving gravitational force and scale contact force.

for which conceptual understanding and language issues were investigated in this study.

Differing usages of terms inevitably cause confusion in teaching and learning physics, especially if the language issues go unrecognized or unaddressed. It seems that the term weight has historical origins in the everyday "weighing" of goods at a market, and the term has somehow carried over to scientific contexts in two different ways. We note that the historical meaning of weight accords more with the practical and operational (scale) definition than with the more abstract gravitational definition, which arose later. The operational definition is also consistent with the experiential notion of "felt weight" and applies without qualification in all situations. Then there is also the more radical question of whether the term weight is needed at all, at least scientifically, as a single-word descriptor for the gravitational force on an object. We could, in principle, do without it. No corresponding term is invented or needed for the electrostatic force on a charged particle or object, or any other kind of force. Nor indeed is the term weight normally used for the gravitational force on an elementary particle: we do not much talk about the weight of an electron or proton, but rather about the gravitational force on it, if that is what is meant. Besides terminology, the grammatical construction of the phrase "weight of an object" tends to suggest that weight is an intrinsic property of an object, whereas it actually refers to an interaction between objects, and this can vary depending on the situation. No wonder students' thinking becomes confused. Paraphrasing Braithwaite [2], once we use the term we risk ending up "in bondage to words of our own creation".

In trying to deal with all these conceptual, semantic, and grammatical issues in teaching, we have come to advocate an approach that avoids using the term weight altogether during initial teaching and learning of the physical concepts in various situations, static and accelerating. (cf. Ref. [3]). Only after the physical concepts are understood and discriminated do we introduce the term weight, explain that there are two usages, and address the language issues explicitly from that point on. The same instructional treatment applies to the concepts associated with the terms apparent weight and "weightless," as well as the term "free fall" which has its own difficulties. Since the term weight is deeply embedded in everyday and scientific usage, the language and terminology issues need to be acknowledged and dealt with, at the appropriate stage, rather than ignored, which is often the case.

In this paper, we first present an overview of language ambiguities and conceptual difficulties associated with weight as discussed in the physics and science education 
literature. We then share our overall project design, which includes both an instructional development and a research component. Central to our project was the initial development of a framework for dealing with language issues in teaching and learning about weight-related concepts. Based on this we describe our rather radical approach for teaching about weight, weightlessness, and free fall, which addresses the associated language issues explicitly. We developed a course module embodying this, and implemented it in instruction. The module was taught by three instructors in different sections of an undergraduate physics course for preservice education students over the course of two semesters. Participants' conceptual learning gains were determined using conceptual pre- and postassessments aligned with specific learning objectives. Participant understandings of the language issues as well as their views on the instructional approach were obtained using surveys and interviews. We also interviewed the instructors for additional insights into the advantages and challenges of teaching weight using this approach.

\section{WEIGHT: LANGUAGE AMBIGUITIES AND CONCEPTUAL DIFFICULTIES}

Words can be polysemous in both scientific and everyday language [4]. Polysemy refers to a word having more than one related meaning. This is at the root of the language usage problem facing the term weight-it has at least two different meanings even in scientific parlance, and these meanings are related though conceptually quite distinct. On the other hand, terms with two unrelated meanings are quite common in everyday language and usually cause less trouble since context readily discriminates meaning. The problem of multiple related meanings as well as everyday usages also arises in physics for other terms such as "heat" and "force." Issues of language and terminology are important not only for learners but also for instructors and researchers, considering how easy it is to misinterpret terminological mismatches as misconceptions about the underlying concepts [5]. Language issues become especially pertinent when a term is polysemous within science, as it is for weight [6].

The term weight is especially problematic in that divergent views exist even among scientists, let alone instructors and textbook authors, regarding how it should be conceptualized and defined [7]. Galili, a physicist and physics educator who has done much of the work in this area, notes that weight continues to be defined in two ways: (i) a gravitational definition, as the gravitational force acting on an object, irrespective of the object's motion; and (ii) an operational definition, as the contact force measured on a scale ${ }^{3}$ regardless of the object's motion or location [8].

\footnotetext{
${ }^{3}$ In our class discussions and throughout the manuscript, the terms "scale force," "scale contact force," and "contact force" have been used interchangeably.
}

Galili strongly advocates using the operational rather than the gravitational definition. He provides good scientific and educational arguments for this, even though the majority of textbooks do the opposite [1]. A recent study by Stein, Galili, and Schur [9] found the operational definition of weight to be reasonably effective across various cases in teaching middle school students. Nevertheless, their study did not set out to explicitly address the linguistic difficulties and ambiguous meanings commonly associated with weight-related terms. Our paper recognizes common difficulties as inherently language related, and our approach to instruction and assessment is framed accordingly.

\section{A. Accelerated systems: Weight, weightlessness, and free fall}

There might not be as much debate about whether the gravitational definition or the scale definition is the "correct" one if both always gave the same value for weight. While they do so in common static situations, they do not in accelerating situations and it is here that further conceptual and semantic confusions arise and bedevil teaching and learning and hinder conceptual understanding. The two definitions yield the same numerical value for simple cases of nonaccelerating objects where the term is usually first introduced, e.g., for an object in equilibrium at rest on a measuring scale. But they give different values in nonequilibrium situations where object and scale are accelerating and where the implicit frame of reference may be noninertial. Thus, in an accelerating elevator or orbiting spaceship, the weight of an object, according to one definition, always remains the gravitational force on it, no matter what its state of motion or what a measuring scale indicates. According to the other definition the weight depends on the state of motion of the object and measuring scale or force sensor. Note that both static and accelerating situations can be described and understood using simple force diagrams and Newton's laws, without using the term weight at all.

In the particular case where an object and a scale move together subject only to the gravitational force (so-called free fall conditions) a measuring scale would read zero contact force. To say that this corresponds to a state of weightlessness makes sense using the operational definition, even though a gravitational force still acts on the object. Thus, according to one definition this object is weightless while according to the other it still has weight (mass $m$ times gravitational field strength $g$ ). To try to deal with such nonequilibrium cases, those using the gravitational definition of weight often introduce adjectival terms such as apparent weight and apparent weightlessness [10], but such semantic attempts to clarify may be seen as hedging and simply lead to further confusion.

The term free fall has also been recognized as problematic by several researchers [11,12], and laden with its own semantic difficulties and conceptual pitfalls for learners. 
While an accelerating object subject only to a gravitational force is a clear physical situation, calling this situation "free" risks confusing learners, because the object is not free from gravity. In addition, the object is generally not "falling" in the usual sense, because the everyday meaning of "fall" is to drop toward the ground. Thus, the words free and fall in free fall motions are not ideal for initial conceptual learning, though scientists understand and even appreciate the rather sophisticated language usage. The scientific meaning of free fall is motion under the influence of gravity only, and it encompasses a wider variety of physical situations and motions than the everyday words imply. It applies not only to an apple falling to the ground, but also to an apple thrown upward and continuing to rise, or a satellite continuously orbiting the Earth, or the moon doing likewise even as we see it rising in the east. Chandler [13] argues that making the conceptual connection between free fall for a dropped object and that for orbital motion is an especially challenging task.

\section{B. Previous studies on students' and teachers' ideas about weight}

Research studies have focused on students' and teachers' ideas about weight and related terms and concepts, including gravitational force and scale force in various situations, and the condition of weightlessness in free fall $[8,9,12]$. These are reported and discussed in detail by Taibu [14] and, more concisely, in a recent study of textbooks' presentations of weight [1]. However, many research studies themselves simply adopt (or assume) a particular definition of weight, seemingly without reflection on or awareness of the nuances and language issues. They tend to couch their questions to students with the gravitational definition in mind, and to interpret students' responses to them in the same way, even where those responses reflect thinking in terms of the alternative meaning and usage. For some such studies, the research design, assessments, interpretations, and findings may thus be questionable. For example, some ideas of weight articulated by children have been characterized by researchers as incorrect misconceptions when they in fact reasonably reflect the operational rather than gravitational meaning of weight. This is always a danger when language and conceptual issues are intertwined - the teacher, student, and researcher may be interpreting terminology differently. This kind of problem unwittingly confounded many earlier studies of student conceptions of force, casting doubt on some of the inferences and conclusions drawn about student misconceptions in that area.

\section{How textbooks treat weight: Research results}

In a previous study we examined how weight, weightlessness, and free fall are portrayed in a sample of 20 textbooks in common use for introductory college and university physics courses [1]. The focus of that inquiry was on what definition of weight textbook authors adopted, whether they explicitly mentioned the alternative definition, and how they treated the language and terminology issues, if at all. We found the majority (80\%) of the textbooks examined used a gravitational definition of weight, while the operational (scale force) definition was much less prevalent (20\%) despite cogent arguments for its advantages by advocates. Half of the textbooks studied had inconsistencies in how they used the term weight no matter how they defined it. Only one textbook [15] explicitly acknowledged the language issues associated with weight by mentioning possible alternative usages. It seems unfortunate that most books ignore the issue.

Books using the gravitational definition introduced weight first in static (equilibrium) situations. Later when discussing nonequilibrium (accelerated) situations they added other qualifiers like apparent weight or "effective weight," and began referring to their original gravitational definition as "true weight," "real weight," "normal weight," or "actual weight." They did this despite having adopted a clear gravitational definition of weight, which would make such additional phrases unnecessary. The adjectival phrases are presumably aimed at differentiating gravitational force from scale force, since both constructs are now being referred to as weight, though with various adjectives attached to distinguish them. Perhaps these naming practices implicitly recognize that, even if weight is defined as gravitational force, people will tend to bring in measuring scale ideas from their prior experience of "weighing" in static situations. The adjectival phases above thus seem to represent some kind of definitional hedging. For situations in an orbiting spaceship, similar hedging phrases like apparent weightlessness arose in textbooks discussing the condition of zero scale force, or else these books cautioned that the term weightless was a misnomer, even while using it. On the other hand, books using the operational definition of weight as scale force did not face these difficulties and did not need additional clarifying terminology. These treatments introduced no special word for gravitational force, but called it gravitational force. The operational definition thus reduced confusion by obviating some verbal gymnastics.

These different treatments, terminologies, and attempted clarifications illustrate the semantic problems that arise when two distinct constructs are known by the same name, weight. Using that name does not add to our understanding of the physical situation or the concepts involved, and brief direct, descriptive phrases will do the job. It would be possible in principle to avoid such confusions entirely if ambiguous terms such as weight and weightlessness were simply eliminated in the discussion of the physical concepts. Yet students will encounter these terms in both everyday and scientific language, so they must become familiar with the problem in order to overcome it.

\section{OVERALL PROJECT DESIGN}

Our project is an attempt to understand how best to teach weight and related concepts, cognizant of the language 
ambiguities and conceptual difficulties discussed above. Instead of accepting the word unquestioningly for initial teaching, and trying to decide which was to be our "correct" or "preferred" meaning, we concluded that our instructional approach should avoid the term weight altogether in initial teaching and learning. Instead, we would teach the two physical constructs and how they relate in various situations, referring to them as needed by the phrases "gravitational force" and "scale contact force." We further realized that, while it was essential that language issues be explicitly discussed, the time to do so would be after students had a clear understanding of the physical concepts and how they are distinct from one another. With this approach in mind, we then focused on developing a logical, coherent teaching sequence using those phrases. We further focused on how best to assess learning for both mastery of content and appreciation of language issues. Our overall project accordingly had two parts: a development component and a research component. Project goals were as follows.

(A) Development goals

(i) Design and develop a new instructional module for the concepts commonly referred to as weight, weightlessness, and free fall.

(ii) Develop sets of items to assess conceptual understanding of these concepts regardless of terminology.

(iii) Develop a survey to assess student understanding of the language issues involved.

(iv) Develop a survey for student attitude toward the approach and module.

(B) Research goals

(i) Implement the new module in an introductory college physics course.

(ii) Assess learning gains for concept understanding.

(iii) Assess students' understanding of the language issues.

(iv) Analyze students' views of the approach and module.

(v) Survey instructors' experiences of the module. Section A discusses how we conceptualized the approach to the teaching of weight. Section B describes the development of the instructional module and associated assessments embodying this approach. Section $\mathrm{C}$ reviews how it was implemented in two different semesters. Section D describes the research methods, data collection, and analyses.

\section{A. Conceptualization of the new instructional approach}

Our own teaching experience, ideas, and review of the literature suggested an alternative instructional approach. General agreement on the definition of weight among physicists and science educators alike is unlikely to occur anytime soon, if at all. Students need to understand each important physical construct by any name, in order to become capable of inferring intended meanings from context and usage of language. Teaching only the operational (scale) definition of weight would have certain advantages over the gravitational definition and is less prone to confusion, but is currently the minority practice. Even if one teaches one's own students one particular definition of weight only, they will encounter it defined the other way elsewhere and should be prepared for this. Hence, our approach is to teach the labeling issue and controversy explicitly, but only after the physical constructs have been understood.

We advocate first teaching each weight-related physical construct in its own right, in each situation, using direct descriptive phrases, while students gain experience and familiarity with the concepts, i.e., emphasizing ideas before introducing special names for them [3]. Afterward, instructors and students engage in explicit discussions of terms and definitions, to inform learning, minimize possible confusions, and increase awareness of and appreciation for the role of language in science and teaching.

Our design approach to the module was thus to introduce the physical constructs of gravitational force and scale force, first for static (equilibrium) cases, then for cases involving acceleration, in each case identifying the specific forces acting on the object and applying Newton's laws to understand force in relation to motion. An instructional design decision was needed about exactly when to bring in the term weight, i.e., whether to delay discussing weight definitions until the very end of the module, after the physics of both equilibrium and accelerated cases had all been treated, or to discuss the term as each specific case was treated. We opted for the latter, partly because students would themselves think of the term anyway from previous schooling or everyday exposure to it, and partly because it seemed best to discuss the terminology issue while the context of each type of case was fresh, rather than revisiting all cases at the end. This decision seemed consistent with the idea that content and terminology are intertwined for this topic.

Therefore, after the physics of static cases was thoroughly dealt with, we brought in the term weight and talked about two possible definitions and the existing lack of agreement. We pointed out that the word is not essential to understanding the physics of the topics. Thereafter, we proceed to the physics of accelerated cases, without using the term, and then brought in the term again and discussed the terminology issues arising. This instructional design also accords with Aron's [3] general credo of "idea first, name afterwards" (p. 102) for teaching any concept, and becomes especially pertinent when a concept name is ambiguous. Kuhn argued [16] that verbal definitions have little scientific content when considered by themselves, especially when presented upfront in advance of concept development, as often occurs in didactic direct instruction. When we do need to use the term weight, we make clear our preference for the historical, operational meaning, but we also explain to students that they will find that most 
textbooks use the gravitational definition, and they will therefore need to discern intended meanings from context.

We had considered a more radical solution to the language difficulties, namely, to eschew the word weight altogether, avoiding it during discussion and discouraging its use by students; after all, we can discuss the physics perfectly well without saying the word. If the term weight were not already so unavoidably ingrained in both scientific and everyday usage, it would seem silly to subject students to terminological convolutions, but that is the current reality that must be dealt with. Furthermore, besides the polysemy problem, one can also make a grammatical case for eliminating the term weight: the way it is used grammatically in sentences may engender misconceptions about the concept [1], as noted before. However, we recognize that the term is not going to go away and thus cannot be ignored. Indeed, language issues are interesting and educational in their own right and worthy of teaching explicitly, given the role that language plays in science. Thus, in our preferred approach we explicitly recognize the polysemous nature of weight-related terms and discuss this as part of teaching the topic, aiming at the root of the confusion, at the same time enlightening students about language in science.

\section{B. Development of the instructional module and associated assessments}

\section{Instructional module}

In view of the foregoing considerations we designed an instructional module for the teaching and learning of weight-related concepts using the following principles:

(1) Concepts to be introduced using descriptive phrases prior to naming them.

(2) Language ambiguities and alternative usages to be made explicit to students.

(3) Meanings should be discerned from context where necessary.

(4) Concepts and scientific terms to be taught in multiple physical situations $[17,18]$.

(5) Language discussions to occur after each case has been treated rather than being left to the end of the module.

Table I shows the module structure in terms of concept units.

The instructional materials produced comprised 40 pages, with content guided by focus questions. Spaces were left for students to write notes and responses. Each section ended with a list of objectives and sets of corresponding assessment items. Further details of the module materials are in Ref. [14].

\section{Lesson example: elevator ride}

We provide a brief description of a lesson activity in the unit for the case of accelerated vertical motions.
TABLE I. Module structure and organization.

Concept unit 1: The gravitational force

1.1 Introduction

1.2 Investigating the gravitational force

1.3 The gravitational force near Earth's surface

1.4 Important points about gravitational force

Concept unit 2: Gravitational and contact forces acting on a nonaccelerating object

2.1 An object on a hard surface

2.2 The scale force

2.3 Relationship between mass and scale force reading

2.4 Weight vs mass

2.5 What does it mean to "weigh" an object?

2.6 The gravitational and scale forces (on Earth vs on the moon)

2.7 Any issues with the term weight on the moon?

2.8 Comparing gravitational and scale forces for an object on different planets

2.9 An object submerged in a liquid

2.10 An object submerged in a liquid: Terminological issues

Concept unit 3: Vertical (linear) accelerated motions

3.1 Activity: Elevator ride and/or thought experiment

3.2 Forces on an object in an elevator

3.3 What can you say about your weight in an elevator?

3.3.1 The case of a broken elevator cable: Physics and terminology

Concept unit 4: Curved accelerated motions: Astronauts in an orbiting spaceship

4.1 What keeps the spaceship in orbit?

4.2 Any scale forces exerted on astronauts in a spaceship?

4.3 The range of the gravitational force

4.4 Using the term weight: in a spaceship

4.5 Using the term weightlessness in a spaceship

4.6 The term free fall and everyday language

Small groups of students took elevator rides. One student stood on a bathroom scale while the group observed how the scale reading varied for different motion stages of the elevator. The stages were as follows: (i) at rest, (ii) accelerating upward, (iii) moving upward at constant speed, (iv) slowing while approaching a higher floor, (v) stopped. Students then drew sets of force diagrams, showing and comparing the gravitational and scale forces acting in each stage and relating this to acceleration. A similar sequence could be carried out for the elevator going down from the higher floor to the ground floor, although in this case the students were asked to predict scale reading behavior in advance, with force diagrams, before observing in practice.

All of the discussions of these situations involving motion, forces, and accelerations occurred without using the term weight, and discouraging it at the time if students mentioned it. The term was only brought into the discussions when the students were clear about the physics of all stages of motion. At that time, ambiguities regarding use of the term weight in this situation were disclosed, debated, and discussed in the concrete context of this activity. 


\section{Assessments}

Assessments for the module were developed to align with learning objectives and instruction, specifically targeting weight-related concepts. The assessment items posed both qualitative and quantitative questions in a variety of contexts, including equilibrium and accelerated situations. The format included both multiple choice and written response questions. Items used descriptive phases (gravitational force and scale force) together with representations such as force vectors and diagrams, rather than using terms like weight and weightlessness. Understanding of language issues was assessed separately with further assessment items devised for that purpose.

The assessment items were refined by taking into account student responses to similar questions piloted in a previous semester. Content and face validity tests $[19,20]$ were conducted to check that the set of items tested content appropriate for the topic and students. Checking content validity involved discussion of the assessment items with experienced physics faculty and instructors, while for face validity the items were piloted with students similar to the target group. Similar items of this nature were used formatively during instruction as part of learning. The piloted and refined set of items (Appendix A) was administered pre- and postinstruction to obtain a summative measure of learning gains.

\section{Implementation of the instructional model}

\section{Course and participants}

The new instructional module was implemented in an introductory physics course called Physics: Inquiry and Insights for preservice elementary and middle school teachers at Western Michigan University in the United States. This particular physics course and student group were chosen because we had ready access to the course and section instructors, and were free to design and implement the new module as a natural part of the syllabus. Furthermore, preservice teachers could one day be teaching this topic to their own students.

The course, partly conceptual and partly algebra based, takes a guided inquiry approach to concept development. It is taught in an integrated lab and lecture studio-style format with theory development and hands-on lab activities intertwined. The course has three sections of 24 students each, meeting regularly twice a week for two studio-style class sessions, each lasting 2 hours and 20 minutes. Students are in groups of four at benches, and the room has a large whiteboard, screen, projector, and lab apparatus. Physics topics and concepts were developed using a mixture of instructional methods, including instructor presentations, explanations, and demonstrations as well as student hands-on activities and experiments, so that core physics ideas and witnessed phenomena were linked. The inquiry-based approach reflects the Karplus learning cycle for the most part [21]. The sections were taught by three experienced graduate students (one of whom is the first author) each having a master's degree in physics and pursuing a doctorate in science education. All sections were overseen by a faculty course coordinator (second author). The research module on weight was implemented over four such class sessions, plus homework assignments, after students had learned kinematics and Newton's laws of motion. As far as possible the module was taught without mention of the term weight, and instructors told students so (if asked). Section instructors were trained through lesson plans, simulated teaching, and meetings with the researcher before and after each class session. Class sessions were videotaped, and the videos viewed by the lead researcher and instructor, to establish fidelity to intended implementation using a classroom observation form and checklist. Any problems identified in lesson implementations led to changes the instructors could make in subsequent sessions. Formative assessments and feedback occurred during instruction for each of the core ideas of the module. A final exam as post-test provided summative assessment of student performance at the end of the course, and comparison with an identical pretest at the beginning allowed us to determine learning gains.

During the Spring 2014 term, 68 students were enrolled in three sections, of whom 57 students agreed to participate in the study. During the Fall 2014 term, 67 students were enrolled, of whom 55 agreed to participate.

\section{Data collection and analysis}

\section{Determining conceptual understandings, learning gains, and effect sizes}

Students ${ }^{4}$ took a pretest containing multiple-choice questions and written response questions before starting the instructional module, and an identical post-test after completing it (Appendix A). Scoring of written responses was aided by rubrics. Two graders (the first author and an experienced physics educator with a master's degree) graded the written responses for about $20 \%$ of the test papers. The interrater reliability (Pearson $r=0.94$ ) indicated a high correlation [22] between the two graders [23]. Discussions then resolved any differences in scoring. The first author then used a refined rubric to score the rest of the written responses. Written surveys and interviews were later used to further investigate participants' conceptual understanding, as well as instructors' and participants' views of the module.

Learning gains were calculated as the difference between pre- and postscores. Learning gains are a measure of "how much students learn" on a topic, taking into account their

\footnotetext{
${ }^{4}$ For ease of expression, from this point onward the word "student(s)" will refer to student participants, i.e., those students who gave consent to have their results shared as part of our research.
} 
starting knowledge $[24,25]$. We also calculated normalized gains, defined as the ratio of the actual learning gain to the maximum possible learning gain given the pretest score. Normalized gain (g) is advocated by Hake [25] (p. 64) for obtaining a rough measure of the average effectiveness of a course or module in teaching the concepts under consideration.

We also calculated the effect size, or Cohen's $d$ [26] of the performance gains arising from the instructional unit. This is the size of the effect obtained (in our case gain), expressed as a multiple of the standard deviation involved, rather than simply as raw gain. The magnitude of the effect sizes resulting from our instructional method could be put into broad context by comparing with representative effect sizes obtained for teaching methods of many different kinds, as reported in Hattie's comprehensive synthesis of 800 metastudies on research on educational effectiveness [27].

\section{Assessment of students' interpretations of weight in equilibrium and accelerating situations}

Students' interpretations of weight in both static and accelerating situations were further explored in two ways, (i) by qualitative analysis of the pre- and post-test written responses, and (ii) by interviewing students after instruction.

A subset of fifteen participants was drawn from the three sections. Participants were each interviewed for about 25 minutes. The second author interviewed those students drawn from the first author's section. An "interview guide approach" was used to explore specific issues, asking specific open-ended questions [20]. Student participants were provided multiple instances to think about, explaining their understanding of the gravitational and scale forces as well as the language issues. This is similar to the "interview-about-instances" technique described by Osborne and Gilbert [28]. Participants were, for example, asked to identify and characterize the forces acting on an object at rest, a submerged object, and an object in an accelerating elevator. A follow-up question asked if either force could or should be called weight. The rationale was to give participants the opportunity to talk about whether the meaning of weight was a matter of definitional choice, and also to explain whether the physics was clear, while demonstrating awareness of terminology. Questions aside from the ones prepared [29] were introduced if the opportunity arose naturally. The basic protocol for the interviews is in Appendix B.

\section{Assessment of students' understanding of language issues and ambiguities}

The interviews were also used as an opportunity to probe students' awareness of language issues and associated terminological ambiguities. The prompts we used to initiate the language conversation are in Appendix B.

\section{Students' views and attitudes}

Students' experiences with the instructional approach and their perceptions and attitudes towards it were elicited in one-on-one interviews [30]. The interviewer engaged the interviewees in "a conversation with a purpose" [31] (p. 149). See Appendix B for examples of the questions we used.

\section{Instructors' views and attitudes}

Interviews with the two other section instructors were conducted during the Spring 2014 term. The first author employed an "informal conversational interview" technique at the beginning, then later an "interview guide approach" [20]. Example questions were: "Please explain your experiences of the instructional process; in what way (s) this approach might be better or worse than the traditional approaches to these concepts found in textbooks? What are your concerns regarding this approach?" Appropriate prompts were made along the way to get as much information as possible. The interview questions were examined by several individuals for bias, sequence, clarity, and face validity.

\section{Qualitative analysis of the data}

In tackling the qualitative data, the first author started by reading the written surveys or transcripts several times to make sense of student responses with respect to the project goals [29]. This generated preliminary coding schemes for the data. The coding of transcripts of participant and instructor interviews was done both by expert judgment and with the help of Hyper-research software. Both inductive and a priori codes were used [20]. A priori codes were the ones we anticipated before the data analysis (e.g., weight is the gravitational force) and inductive codes were those generated after looking at the data. Most of the qualitative analysis of the pretest and post-test written responses was conducted by coding participants' pre- and postresponses side by side.

Interview responses from the 15 participants as well as interviews from the two instructors were transcribed and analyzed through coding and categorizations of response data [32]. Note that "coding" entails identifying specific knowledge such as weight is the gravitational force due to the Earth. On the other hand, "categorizations" refers to the fact that we grouped all similar codes into one category. The interview questions had been examined by several individuals for bias, sequence, clarity, and face validity [33]. Reliability in coding was established by two individuals through discussions and by consensus [34].

\section{RESULTS AND DISCUSSION}

Here we provide the data, analyses, and results of the study. Both student and instructor data are involved. Data and results for students include pre- and post-test scores, 
TABLE II. Comparison of mean scores between pretest and post-test (Spring 2014).

\begin{tabular}{llcccccc}
\hline \hline Class & $\mathrm{N}$ & $\begin{array}{c}\text { Pretest score } \\
\text { out of 43 (SD) }\end{array}$ & $\begin{array}{c}\text { Post-test score } \\
\text { out of 43 (SD) }\end{array}$ & $\begin{array}{c}\text { Raw } \\
\text { gain }\end{array}$ & $\begin{array}{c}\% \\
\text { Gain }\end{array}$ & $\begin{array}{c}\text { Normalized } \\
\text { gain }\end{array}$ & $\begin{array}{c}\text { Effect } \\
\text { size }\end{array}$ \\
\hline A & 20 & $14.0(6.6)$ & $36.7(6.0)$ & 22.8 & 52.9 & 0.78 & 3.6 \\
B & 18 & $14.1(6.5)$ & $32.9(4.2)$ & 18.8 & 43.7 & 0.65 & 3.4 \\
C & 19 & $14.7(7.4)$ & $34.0(6.4)$ & 19.2 & 44.7 & 0.68 & 2.8 \\
All & 57 & $14.3(6.8)$ & $34.6(5.8)$ & 20.3 & 47.3 & 0.71 & 3.2 \\
\hline \hline
\end{tabular}

TABLE III. Comparison of mean scores between pretest and post-test (Fall 2014).

\begin{tabular}{llcccccc}
\hline \hline Class & $\mathrm{N}$ & $\begin{array}{c}\text { Pretest score } \\
\text { out of 51 (SD) }\end{array}$ & $\begin{array}{c}\text { Post-test score } \\
\text { out of 51 (SD) }\end{array}$ & $\begin{array}{c}\text { Raw } \\
\text { gain }\end{array}$ & $\begin{array}{c}\% \\
\text { Gain }\end{array}$ & $\begin{array}{c}\text { Normalized } \\
\text { gain }\end{array}$ & $\begin{array}{c}\text { Effect } \\
\text { size }\end{array}$ \\
\hline A & 20 & $16.6(6.3)$ & $37.1(7.2)$ & 20.5 & 40.3 & 0.60 & 3.0 \\
B & 14 & $10.5(6.1)$ & $42.6(4.1)$ & 32.1 & 63.0 & 0.80 & 6.2 \\
C & 21 & $12.5(5.2)$ & $41.5(7.2)$ & 23.0 & 56.8 & 0.75 & 4.6 \\
All & 55 & $13.5(6.3)$ & $40.2(6.9)$ & 26.7 & 52.3 & 0.71 & 4.1 \\
\hline \hline
\end{tabular}

learning gains, normalized gains, and effect sizes, as well as students' understandings of the language issues and views of the instructional approach. Results for instructors include their experiences teaching the module and their perspectives regarding the new approach to this topic.

\section{A. Students' conceptual understandings}

Table II and III show the class pre- and post-test scores, standard deviations, calculated raw and normalized gains, and effect sizes, for the three class sections A, B, and C, in spring and fall semesters of 2014. Numbers are rounded to two or three significant digits as appropriate since further digits would not be meaningful. Appendix A presents the pre-post test that was used in Fall 2014. The Spring 2014 pre-post test is available in Ref. [14].

\section{Normalized gains}

The average normalized gain (for all classes over both semesters) was 0.7, which is considered high [25] given that the maximum obtainable is 1.0. The result may be put into context by noting the typical normalized gain results compiled by Hake [25], from studies using the Force Concept Inventory (FCI) in many introductory physics courses or dynamics modules. These normalized gains ranged from about 0.2 for "traditional" courses to about 0.35 when using "active learning" methods, with some results higher than this. This range gives a useful scale to rate normalized gains obtained as low, medium, or high. Our result of 0.7 was for conceptual understanding in a two-week unit focused on a specific topic area, namely, gravitational and contact forces in various equilibrium and accelerated situations, and tested immediately preand postinstruction. For the FCI, one often sees results reported as associated with a mechanics course or dynamics module, but note that the FCI is a conceptual test focused only around the target concept of force, in basic static and dynamic situations, which topic occupies only part of a course. Thus, it seems appropriate to use reported FCI normalized gains to give broad comparative context to our results for the weight unit, although the topics are different, since both involve conceptual physical understanding rather than formalism, and both aim at selected physics concepts which form part of a mechanics course.

Table IV presents normalized gains for each of the eight multipart assessment questions separately, as well as the overall normalized gain for Spring 2014 and Fall 2014. Gains ranged from medium to high for all the questions in all semesters. The results below give evidence of notable gains in students' situation-independent conceptual understanding [17].

\section{Effect sizes}

The effect sizes [35] obtained for the unit are also tabulated in the last column of Tables II and III. The average effect size obtained across the three classes was 3.2

TABLE IV. Normalized gains for each situation considered.

\begin{tabular}{lcc}
\hline \hline & \multirow{2}{*}{ Normalized gains } \\
\cline { 2 - 3 } & Spring & Fall \\
Situation & 2014 & 2014 \\
\hline Elevator moving at constant speed & 0.78 & 0.90 \\
Elevator accelerating upward & 0.56 & 0.64 \\
Elevator accelerating downward (not falling) & 0.42 & 0.70 \\
Elevator dropping freely & 0.67 & 0.64 \\
On the moon or with reference to other & 0.77 & 0.75 \\
$\quad$ situations & & \\
Buoyancy & 0.86 & 0.85 \\
Spaceship & 0.70 & 0.64 \\
Overall normalized gain & 0.68 & 0.71 \\
\hline \hline
\end{tabular}


for the Spring 2014 semester, and 4.2 for the following Fall 2014 semester after some course refinement. These large effect sizes are indicative of substantial learning over the course of instruction [25], of clear practical significance not just statistical significance. These values are at the high end of results in Hattie's synthesis [27] of research metaanalyses providing the range of reported effect sizes for many different teaching strategies. Hattie notes that "all methods work" in that they produce some positive learning beyond zero gain (not exactly a high bar), and that an effect size of at least 0.4 is only to be expected simply because instruction has been provided. Thus, to be called relatively "successful" in real teaching terms, a method has to demonstrate an effect size of at least 0.5 , and preferably considerably more.

\section{Discussion}

For our study, both the normalized gains and effect sizes for all classes and all three instructors are relatively large, even exceptional. Student performance gains for conceptual understanding of the physics concepts over the course of the unit thus exceeded our expectations. This lends credence to the viability of the new approach in a topic where students are known to have difficulties, and where various "alternate conceptions" are common [8,36,37].

We are not sure what might be the various reasons for the gratifyingly large gains and effect sizes for this instructional unit and approach. One could be that most aspects of the topic as taught were initially new and unfamiliar to the students, so that they started with very low prescores, not much better than the pure guessing rate of $25 \%$ on fouroption multiple-choice items, while at the same time the class score distributions were fairly narrow, in terms of standard deviations. High gains and small standard deviations together lead to large effect sizes. The narrow distribution postinstruction is also pleasing, indicating that most students benefited from the instruction, rather than some a lot and others little. Furthermore, our impression from instruction and interviews is that students found the unit new and interesting, and many of the ideas and situations intriguing, perhaps more so than for regular topics; and this may also have been a factor in improved learning, along with instructor enthusiasm.

\section{B. Students' interpretations of weight in static and accelerating situations}

Figures 2 and 3 show the distribution of responses in the pre- and post-tests on students' ideas of weight (Appendix A, question 9B).

Pre-instruction, ideas of weight reflecting notions such as the perceived heaviness of an object, or how much an object weighs, or what the scale reads, all point to a notion of weight as related to a scale force, while other ideas pointed to notions related to gravitational force (Fig. 2). However, such informal definitions lacked scientific

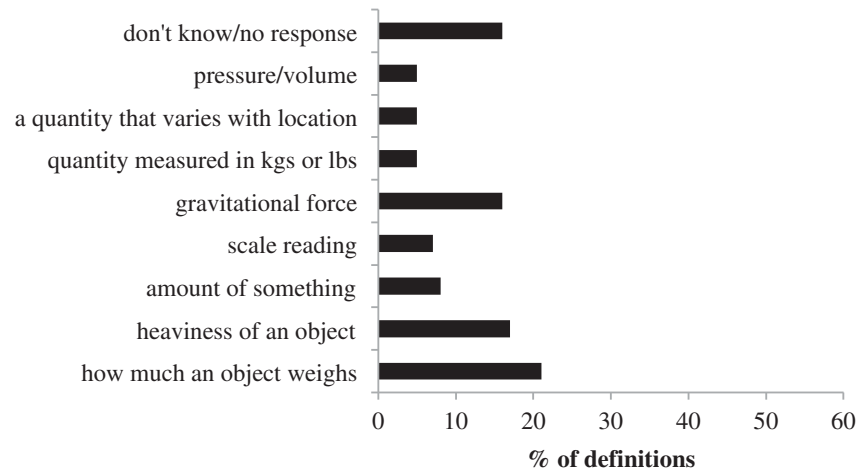

FIG. 2. Definitions of weight, pretest.

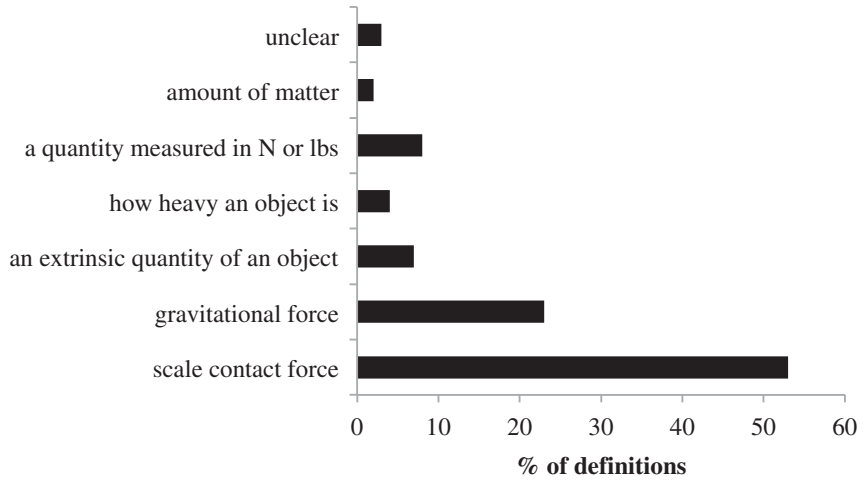

FIG. 3. Definitions of weight, post-test.

precision. After instruction, as shown in Fig. 3, students developed more formal and precise views of weight as being either the scale contact force or the gravitational force on the object.

After instruction most students in these classes were able to give both definitions and noted the language issues, although this is not demonstrated in Fig. 3. The categorization does not take into account the various compound (multiple) definitions that students mentioned, but it appears that most of the definitions were in terms of the scale contact force. Note that this analysis focused only on the various referents students attached to the term weight. The next section explores whether students referred to one or more possible definitions.

\section{Students' understandings of language issues and ambiguities}

This section presents findings as to what extent students recognized and dealt with the language ambiguities.

\section{Students' preferences for how to define weight}

Scientists and educators have given diverse opinions regarding how the term weight should be defined, and we asked this also of our preservice teachers. We present the results of the analysis of 21 students' preferences for how to 
define weight, after instruction. ${ }^{5}$ Preferences are presented as (a) scale force, (b) gravitational force, and (c) recognition of both definitions.

(a) After instruction, 11 of the 21 students preferred the scale force definition of weight, ${ }^{6}$ citing various reasons including that it (i) makes more sense, (ii) is easier to comprehend, (iii) relates well to weighing and weightlessness, (iv) distinguishes weight and mass for a submerged object or an object in free fall, and (v) is what they are used to measuring in their everyday lives. Note that a few students whose postsurveys were analyzed happened to also be interview participants (both the analyzed written surveys and interview participants were randomly chosen). Interviews were conducted to further probe student views and for that reason similar questions were involved in both the written survey and interviews. We found this useful for data triangulation [38] and for responses to quote from the interviews. Here is an example which, although vague, demonstrates preference for the scale force notion of weight:

"Just because I feel like you can kind of like see it and I think it's something easier to understand or conceptualize something if you could see it, it's really hard for us to see gravity, in motion." (S 2)

(b) Three of the 21 students preferred the gravitational definition, citing that just because one cannot measure weight during free fall it does not mean absence of weight. One student noted that weight as a gravitational force is always there, and that it is easy to make sense of. Here is an example quote.

"So it is always with you, if you view it as a scale force, just because there is no contact force, you think there is no weight, but I think that way, weight is always with you, you just can't measure it at certain times, depending on where you are at." (S 5)

(c) Seven of the 21 students indicated no preference, saying that it all depends on the context within which the term is used. Such students noted that they understood both, while others noted that consistency may help in scientific communication. Here is an example quote:

"I have no preference, I understand both concepts equally, I will look for context clues to see which way makes sense, the gravitational or scale force." (S 7).

It is clear that most students understood both the physics and the terminological issues, and they were fairly competent and confident in explaining the conceptual and

\footnotetext{
${ }^{5}$ The choice of 21 students was deemed sufficient after reaching saturation in coding responses.

${ }^{6}$ Probably, the use of the term "scale force" might explain why most students' preferred to define weight operationally since they normally use a "scale" to measure their own weight.
}

language issues. This indicates reasonably good attainment of the objectives of the module.

\section{Students' interpretations of weightlessness in free fall situations}

Table V presents the distribution of students' views related to the term weightlessness in free fall situations, in both the pretest and post-test (Appendix A questions 8, 9C, 9D). It also shows students' definitions of free fall. The incorrect idea that there is no gravitational force on an object in an orbiting spaceship was prevalent among student participants before instruction. After instruction, their explanation of weightlessness was most closely associated with the notion of weight as scale contact force.

Forty-four percent of the conceptions after instruction indicated students' view of weightlessness as a real sensation or experience of the absence of weight (a reality to the person).

\section{Students' awareness of language issues regarding the term weightlessness}

The interviews (Appendix B) probed students' awareness after instruction of language issues regarding the term weightlessness. Fifteen students were interviewed. An example quote indicating good understanding is as follows:

"The only force in action on the spaceship and the astronaut is gravitational force and there is no scale force, so because of that they look like they are in "weightlessness" and I am putting that in quotes because it depends on how you look at it because some people argue that you do have weight because weight is a gravitational force others say you are weightless because there is no scale force ... but it's just a controversy." (SE)

Responses of this nature indicate that many students were confident and articulate in their explanation of conceptual and terminological issues surrounding weightlessness.

\section{Students awareness of language issues regarding the term free fall}

The study anticipated that the term free fall might initially be confusing for students because of everyday language associations for the component words free and fall. Pretest responses confirmed this, when students associated the term only with a situation like a dropping apple, for example (Appendix A question 8, 9C). In everyday language, fall means drop closer to Earth, while in science usage an object in free fall might be moving in various ways, even rising or orbiting. We also anticipated that the word free in free fall might be misleading for students, and indeed, before instruction, some thought this referred to motion without any force. Students' ideas on free fall pre-and postinstruction are provided in Table V. 
TABLE V. Student conceptions of weightlessness and free fall, pre- and pos instruction.

\begin{tabular}{|c|c|c|c|}
\hline \multicolumn{2}{|c|}{ Weightlessness } & \multicolumn{2}{|c|}{ Freefall } \\
\hline \multicolumn{2}{|c|}{ Pre } & \multicolumn{2}{|l|}{ Pre } \\
\hline Conceptions & Frequency $(\%)$ & Conceptions & Frequency $(\%)$ \\
\hline Zero or little force or gravity & 35 & Falling with no force & 31 \\
\hline Don't know or no response & 35 & No response or don't know & 25 \\
\hline Having or feeling no weight & 18 & Falling to ground under gravity & 23 \\
\hline Massless & 5 & Falling without restriction & 11 \\
\hline Floating & 4 & Dropping & 10 \\
\hline Falling & 3 & & \\
\hline Post & & Post & \\
\hline A reality, zero scale force & 44 & Motion under gravity only & 46 \\
\hline Feeling no weight & 33 & Doesn't necessarily free or fall & 26 \\
\hline Free falling situation & 11 & Unclear & 11 \\
\hline Zero or less gravity & 9 & Dropping due to gravity & 8 \\
\hline \multirow[t]{2}{*}{ Unclear } & 3 & Motion with little or no gravity & 7 \\
\hline & & Weightless & 2 \\
\hline
\end{tabular}

Students' views of free fall became more exact and scientific after going through the instructional module. It was pleasing to find that students correctly referred free fall to motion under gravity only ( $46 \%$ of the conceptions), with $26 \%$ going further by noting the language issues that are associated with the term free fall. More evidence about student thinking was provided by the interviews. After instruction, students recognized possible word usage issues associated with the term free fall and could identify various specific cases as free fall situations. They recognized those situations as either motion under gravity only or motion with no scale contact force. The way they spoke about it demonstrated awareness of language nuances for the term free fall. Here are example quotes from students with good understanding.

"Free fall could be misleading because of the two words that make it up. People could assume that 'free' means there is no force acting on it, it is just going and then 'fall' that is going to come down, but honestly free fall means that any motion, upward or down as long as only gravity is in action." ( $S B)$

"Free may be viewed as free from contact force, but there is still a gravitational force; a fall would be not really in terms, fall, but in the sense of gravitational force pulling you." (S L).

Such responses indicated that after this instructional approach most students understood both the physics and the terminological issues. Physics educators have noted that students have problems conceptualizing various situations as being free fall [12], and this module seems to have been successful in addressing such difficulties.

\section{Participants' views about this approach to teaching weight-related concepts}

As described in Sec. III. D, students were asked to explain whether and how the use of multiple situations helped them in understanding the physics behind weight, weightlessness, and free fall. Table VI presents the themes generated from 21 randomly selected student postsurveys. Note that the total number of codes might not equal the number of students, because the unit of analysis was the text and not students. This takes care of views that a single student might have provided more than once. Results and example quotes are given in Table VI.

Table VI contains the following main categories: (1) students' views about the use of multiple physical contexts, (2) students' views about "ideas first, terminology after," and (3) students' views about teaching the language issues.

Table VI indicates that students came to see the use of multiple situations in instruction as helpful in many ways. Accordingly, students were able to see an educational value of the instructional sequence. This is also consistent with good learning gains reported above in this study (Tables II and III).

Initially, while the forces on objects were being discussed in multiple physical contexts, the approach avoided the polysemies associated with weight, weightlessness and free fall, employing direct phrases instead. As shown in Table VI, working with direct phrases (gravitational and scale forces) at the start proved to be useful and productive for most students, consistent with the high learning gains obtained. The performance data, surveys, and interviews all provide support for the approach of avoiding the terms initially when introducing the physical concepts.

\section{E. Instructors' views about approach to teaching weight-related concepts}

Interviews with instructors were conducted using the interview guide in Appendix C. Four main themes emerged from these interviews, as follows: 
TABLE VI. Students' views of the instructional approach.

Views about the use of multiple physical contexts

Helped to view weight as the scale force (2)

Helped in better understanding because multiple situations, multiple examples (3)

It helped to show how forces vary before introducing technical language (1)

It helped because it showed weight is ambiguous (5)

It helped to identify the differences between the scale and gravitational forces (6)

I understood how gravity affects you in different situations (1)

Helped understand the terms; weight, weightlessness, and free fall (2)
Exemplar quotes

"I determined that weight is only possible if there is an opposing force against gravity. So no scale force $=$ no contact force $=$ no scale reading" (S 13)

"Situations helped me because you get a better understanding when the situations have different circumstances" (S 6)

"Helped show the variations of the forces before we introduced confusing terminology" (S 10)

"Actually going into the elevator and watching the scale change helped me to understand the problems with weight" (S 11)

Multiple situations "helped to identify differences in scale force and gravitational force" (S 12)

"It helped me understand where Fs is present and where it isn't" (S 8)

"They were very helpful with how I understood how gravity affects you in different environments" (S 2)

"The use of these situations helped me understand the 'weight, weightlessness, and free fall' much better. It was easy to understand with examples with elevators because we could see what was happening" (S 6)

\begin{tabular}{|c|c|}
\hline Views about "ideas first before terminology" & Exemplar quotes \\
\hline $\begin{array}{l}\text { It helped to demonstrate that there might be complications } \\
\text { if the terms are unclear (2) }\end{array}$ & $\begin{array}{l}\text { "It helped because I saw the different circumstances that would change } \\
\text { the values of gravitational and scale forces, so that would cause } \\
\text { complications if the terms are unclear" (S 15) }\end{array}$ \\
\hline $\begin{array}{l}\text { Helped understand the physics, which in turn helped } \\
\text { in the understanding of terminological issues }(8)\end{array}$ & $\begin{array}{l}\text { "I developed an understanding of the forces, which helped me } \\
\text { understand the terminology" (S 10); "I think it would benefit them } \\
\text { presenting them later to not overwhelm them with a lot of content } \\
\text { knowledge. I would do the same or gradually present the language } \\
\text { problems" (S 9) }\end{array}$ \\
\hline I learned that the term weight is open to interpretation (4) & $\begin{array}{l}\text { "Instead of putting a straight only one way to write weight definition on } \\
\text { weight, you leave it to your own interpretation" }\end{array}$ \\
\hline Helped realize issues with the use of terms (2) & "Yes, see how it gets confusing" (S 13) \\
\hline $\begin{array}{l}\text { Waiting to discuss the terms later set others into } \\
\text { confusion (3) }\end{array}$ & $\begin{array}{l}\text { "I think it's important to reveal language problems in the beginning, so } \\
\text { they know what to look for and don't get confused by a topic } \\
\text { immediately" (S 4) }\end{array}$ \\
\hline
\end{tabular}

Views on making language issues explicit

Reveal language problems, so students can communicate ideas successfully (2)

Reveal to help better understanding of concepts (3)

Reveal the language difficulties or any other confusion (5)

Reveal language issues to avoid further issues at high school (2)

Reveal for the sake of general awareness of the issue (2)

Confusing at first encounter, but easy after discussion: Reveal to be able to interpret weight in context (2)

Depends on the level of students. Reveal only if they ask, can confuse students (1)

Reveal, so students should be careful with their use of ambiguous terminology (1)

\section{Exemplar quotes}

"Yes, it is something students should be aware of so they can communicate their ideas successfully" (S 14)

"I think it's extremely important to reveal language problems to students. Unless the problems are revealed, students will have a harder time truly understanding these concepts" (S 4)

"I think you need to be clear with your students; if there is confusion, address it!" (S 12)

"I would like to because it will cause less trouble as they go through high school" (S 15)

"I would do more hands-on" activities to help them determine the difference" (S 16)

"Weight was confusing to me at first, but when we decided that is was based on the context of the question that helped" (S 2)

"Well, I will be teaching first grade so I probably won't correct them unless they ask. It will just confuse them" (S 4)

"Definitely, I would want them to understand that language can have ambiguous meaning and that we need to be careful with how we use such terms" (S 5) 


\section{Avoiding the terms at the beginning}

Before embarking on this study, the authors and instructors alike were intrigued but apprehensive about the experiment of deliberately avoiding the term weight entirely in initial instruction, since the term is so common in both everyday and scientific language. Results from interviews with instructors indicated that there were indeed some challenges at the beginning. For example, an instructor states

"I stumbled a couple of times at first, I am so used to saying weight, at least three or four times; I can remember catching myself saying the word weight before it was addressed in the packet."

The four instructors (including the first author) noted that many students themselves brought in the term weight.

One instructor notes: "students could find themselves using the term 'weight' when asking questions." When this occurred, students were told that weight was a problematic term which could cause difficulties, and it would be explored later in the module ("It's complicated and we will discuss it later"). ${ }^{7}$ Despite this, instructors acknowledged that with good preparation and awareness, consciously avoiding the ambiguous terms should not be a continuing problem. For example, "it shouldn't be difficult, I was a little bit drained by the time we got to this, but I should be better next time ..." Instructors stressed the fact that they generally liked avoiding the term weight in their teaching. For example, "I like staying away from weight." One instructor thought that students would not like having all terminology left entirely to the end. "I think the students did not like having terminology at the end." When probed to expand on this, the instructor noted that it was better to bring in terminology immediately after discussing each physical context: "introduce weight after discussing each physical context and not after all contexts."

\section{Revealing the language and terminology ambiguities}

One of the credos adopted for this study is that students be explicitly told about polysemous terms and language ambiguities. Instructors reported having discussed the language issues with students and that it was important to do so. For example,

"I talked about everyday language, that it [weight] can be confused with mass, and in physics it can be one of the two forces".

"It's very helpful to make it explicit because otherwise, one of the biggest problems in physics is everyday experiences, gravity is also another dangerous one, it

\footnotetext{
${ }^{7}$ Please note that the "unintentional" use of the term weight by both students and instructors was not frequent. Students learned fairly quickly to avoid using the term.
}

can mean force of gravity, the acceleration, or it can mean weight. Language can be very confusing and it can hamper students' ability to answer questions or to understand things, so it's good to explicitly teach about it".

Putting it in another way, one instructor stated that instructors must "reveal language difficulties to avoid leaving students in suspense," and another one said, "revealing language difficulties is an intellectual honesty." However, one interesting thing that arose from the interviews is that both instructors thought that language issues could be more of an issue for introductory physics nonmajors than for intermediate or higher level physics. For example, "language issues could be more important for nonmajors" and "if someone is going to continue in and major in physics, I don't really care, but for those who just take introductory courses it's important they know, in the real world to be able to understand what surrounds you, you need to understand the differences." Both instructors also noted that textbooks that define weight in one way need to be supplemented by notes discussing language issues, and that textbooks are generally problematic in this regard. "I will supplement what is missing" and "Yeah, there is definitely a problem with that, it lacks singularity, you've got two definitions for the same exact word, it's like a function, if say, you put in something and that function has two outputs, then you are doomed."

\section{Knowledge of the language issues}

Of the two instructors participating, one "preferred" the gravitation definition and the other the scale contact force definition. The one preferring the gravitational definition stated that it helps in problem solving and the one preferring the scale contact force definition stated that it relates to how weight is measured. A quote from the first is

"weight as a gravitational force helps in problem solving, to calculate weight, multiply mass by gravitational acceleration."

A contrasting quote from the second is

"for me I like scale force, it is better, when people think about weight, they don't even think about force, even when you ask them, and they say it isn't mass, they don't think that if it's not an inherent property, something is going on in order to measure it. This measurement goes with force, force is like the primary tenet of all Newton's laws, classical dynamics and the like."

It is interesting that even after explicitly discussing the issue and experience of teaching the new approach, these two instructors had different ideas on which possible definition they preferred if they had to choose-just as is the case among physicists and textbooks. Although both 
indicated their preference, they noted that in their teaching they did not take a side ("not at all, I displayed it as a confusing term") and that they both agreed that students should be made aware about the existence of both definitions. One instructor revealed that he did not know of the existence of two definitions before, but now that he knew, he acknowledged the need to teach both:

"I have always known weight as a gravitational force, it is more useful. I know the word 'weight' is confusing but I have never bothered to find out, because the definition of weight as gravitational force matches up with problems, and it's useful...But I now know that both are correct in different contexts, since I know, and with what I have gone through teaching that, I think it's useful to teach both; that is, to teach them that there are two meanings for the term 'weight,' I think that is a good idea."

Another interesting finding from the discussion with instructors was their view regarding whether or not disagreements exist on how to define weight among experts. One noted that experts are unaware of the ambiguities "They are experts, so they don't know the difference, like myself, I am an expert, I didn't know the difference." Another instructor thought there was no disagreement among scientists or experts. "I don't think there is a disagreement among scientists, but authors on how to disseminate the terminological issues."

\section{Teaching the two constructs in multiple contexts}

One of the conceptual frameworks and design principles for this study was that concepts and terms should be discussed in multiple physical contexts to achieve contextindependent conceptual understanding for learners [17]. Of the five physical contexts explored, instructors felt that the orbital motion discussion of gravitational and scale forces was relatively hard for them to explain and for students to grasp. Instructors noted that the buoyancy demonstration went well: "buoyancy is a difficult concept but you have a good demonstration on that, they see it." For the elevator,

\section{"I liked the elevator portion, but this one on the Newton canon experiment they had trouble with this [here the instructor was trying to point out that the elevator case was better than the spaceship case]. Because we just tell them, maybe we can have an interactive simulation; it could help with weightlessness too," "I think my students got that weightlessness is lack of scale force, but I couldn't get them to explain why there was no scale force, when they are orbiting, when there is a gravitation force."}

For the object on the moon surface one instructor reported that students had trouble explaining the reduced gravitational force on the moon using the universal law:
"For the moon thing, it showed early in class we just didn't continuously touch on it. The idea of the nature of gravitational force as it relates to mass was tackled but they never used it to explain the principles."

Despite these challenges in teaching the gravitational and scale forces in multiple situations, one instructor noted that "the first three sections were simple; but just for section IV (terminological issues) it was not enough," although he further acknowledged that the assessment items helped to supplement this section. "That seemed to flow very well, they were confused but the questions were really helpful, they thought that was very helpful."

\section{CONCLUSIONS}

It is clear that before instruction students had vague and ill-formed views of the concept of weight. For example, weight was thought of as a combination of mass and gravity, or how heavy an object is, or the term weight was equated to mass. These notions have also been found in a variety of previous studies [39-42]. After instruction, however, students' interpretations of the term weight were either the gravitational or the scale contact force definition, and they were aware of both possibilities, and such definitions were clearer and more accurate than before instruction. Additionally, most students, if they had to choose, would prefer the operational scale force definition, while others did not wish to choose, citing that they were comfortable with both and that it was a matter of opinion and definition. This reflects a certain sophistication about the issues.

For the concepts and terms of weight and weightlessness in free fall situations, before instruction, the idea of weightlessness was explained mostly in terms of no gravity in the spaceship. This is a similar result to that obtained by Tural, Akdeniz, and Alev [43] in their qualitative comparison of pre- and post-test understanding of weightlessness among student teachers. These and other authors have attributed this incorrect idea to the definition of weight as a gravitational force in the curriculum, presumably because if there is no sign of motion (relative to the spacecraft) the object is thought not to have weight and hence no gravitational force on it. In our study, after introducing students to both definitions of weight, when we got to free fall situations the incorrect idea of no gravity in a spaceship was relatively rare among students' responses. The most common response after instruction was that weightlessness refers to the absence of scale contact force on an object. This is not a surprise considering that most of them also indicated a preference for the scale force definition of weight. In our study, prior to instruction, students mostly associated weightlessness with astronauts in a spaceship. However, after instruction, they noted that all objects accelerating under the influence of gravity only could be said to be weightless. Several responses from the interviews 
indicated that students were confident and articulate in their explanation of conceptual and terminological issues surrounding weight and weightlessness.

Students gained a greater understanding of the term free fall over the course of the instruction, which initially avoided and later explicitly addressed the linguistic ambiguities of the term. These ambiguities emerge from associations of the words free and fall, as supported by student pretests. Some students associate the term free with objects moving under no force, neither gravitational nor contact forces. Others associated free fall with a dropping object (only), probably because of the term fall. After instruction, students were aware of the language issues and of various situations that are free fall cases (e.g., orbiting astronauts). They recognized those situations as motion under gravity only and with no contact force. This is a good indication that students understood both the physics concepts and how they relate to terminological issues.

Galili [8] advocates the scale force definition as superior for explaining weight and weightlessness consistently. He strongly and convincingly advocates teaching this operational definition (not the gravitational definition) and urges that curricula and textbooks should do so. We think that teaching about only one definition, whichever it is, and even if it is the scale force definition, which has many advantages, inevitably risks confusion further along. Students will inevitably encounter other definitions and usages elsewhere, and should be made aware of the ambiguities inherent in polysemous terms. Our approach differs in that it advocates teaching no definition initially, and not even using the term weight, but instead using descriptive phrases to develop the physical concepts before making students aware of the naming and semantic issues.

Substantial learning gains were obtained during the course of this instructional unit in three classes taught by three instructors over two semesters. The unit focused on two central constructs, gravitational force and scalecontact force, in a variety of equilibrium and accelerating cases and situations, using an approach which avoided confounding terms such as weight at first, and then addressed the associated language issues explicitly. Learning gains, measured by both effect size and normalized gain scores, were both statistically significant and practically substantial, providing evidence of the impact of the instructional unit and approach.

Learning gains were substantial not only when viewed in aggregate, but for each question and physical context, e.g., for an object in equilibrium or in an elevator, on the moon, in a spaceship, or immersed. These learning gains were observed despite the difficulties reported for students in consistently applying their conceptual knowledge to varied scenarios and physical contexts $[8,17,40,44]$. Fostering this level of learning gains for situationindependent conceptual understanding was one of the goals of the intervention.
Based on our experience teaching the module and the gratifying student performance and interview responses, we think that our approach helped greatly in making the central concepts and distinctions clear and understandable, and this was supported by the students' and instructors' views of the module. Besides demonstrating large conceptual gains, students also expressed intellectual satisfaction at understanding both the physics and language issues in some depth.

\section{ACKNOWLEDGMENTS}

We thank Alvin Rosenthal, Janice Marie Fulford, Cody Williams, Aekam Barot, and Lloyd Mataka for constructive comments and suggestions on various aspects of the project. David Cassidy and Bryan Moore taught the new unit along with the first author, and provided valuable feedback and suggestions. David Cassidy also advised on statistical and inference questions. Betty Adams, being proficient and thoughtful in both physics and writing, provided invaluable expert editing of successive manuscripts, including insightful modifications as to how the physics and language issues were presented. Finally, we appreciate perceptive and valuable comments from two anonymous reviewers.

\section{APPENDIX A: CONCEPTUAL TEST (51 POINTS, FALL 2015)}

Note that grading was done only in places where the ambiguous terms such as weight were not used. For example, questions 1 through 4 are worth 5 points each: 3 points for correctly choosing the correct changes (if any) on the mass, contact force, and gravitational force, and 2 points for explanations using force diagrams. Any option or question containing the term weight was not graded to allow students to think about the physics without the ambiguous terms. Thus, only questions 1 through 7 contributed to the score for our learning gain calculations. The same scoring criteria were applied to the Spring 2016 concept test leading to a maximum of 43 points. The survey, as well the questions that were analyzed, all are shared in Ref. [14].

Questions 1-4:

You have a mass of 60 kilograms, and when you step on a bathroom scale in a stationary elevator it reads a scale contact force of $600 \mathrm{~N}$. Answer the following questions about how your mass, your weight, the scale contact force, and the gravitational force may change in each new situation:

Question 1 (5 points)

\begin{tabular}{lllll}
\hline Your mass & Zero & $<60 \mathrm{~kg}$ & $60 \mathrm{~kg}$ & $>60 \mathrm{~kg}$ \\
Your weight & Zero & $<600 \mathrm{~N}$ & $600 \mathrm{~N}$ & $>600 \mathrm{~N}$ \\
Scale contact force & Zero & $<600 \mathrm{~N}$ & $600 \mathrm{~N}$ & $>600 \mathrm{~N}$ \\
Gravitational force & Zero & $<600 \mathrm{~N}$ & $600 \mathrm{~N}$ & $>600 \mathrm{~N}$ \\
\hline
\end{tabular}

The elevator accelerates upward. 
Please circle one response in each row of the table to the right.

Draw a force diagram (of force(s) acting on you), and then explain your responses for scale contact force and gravitational force (in terms of physics concepts and principles).

Question 2 (5 points)

\begin{tabular}{lllll}
\hline Your mass & Zero & $<60 \mathrm{~kg}$ & $60 \mathrm{~kg}$ & $>60 \mathrm{~kg}$ \\
Your weight & Zero & $<600 \mathrm{~N}$ & $600 \mathrm{~N}$ & $>600 \mathrm{~N}$ \\
Scale contact force & Zero & $<600 \mathrm{~N}$ & $600 \mathrm{~N}$ & $>600 \mathrm{~N}$ \\
Gravitational force & Zero & $<600 \mathrm{~N}$ & $600 \mathrm{~N}$ & $>600 \mathrm{~N}$ \\
\hline
\end{tabular}

The elevator is moving at a constant speed.

Please circle one response in each row of the table to the right.

Draw a force diagram (of force(s) acting on you), and then explain your responses for scale contact force and gravitational force (in terms of physics concepts and principles).

\section{Question 3 (5 points)}

\begin{tabular}{lllll}
\hline Your mass & Zero & $<60 \mathrm{~kg}$ & $60 \mathrm{~kg}$ & $>60 \mathrm{~kg}$ \\
Your weight & Zero & $<600 \mathrm{~N}$ & $600 \mathrm{~N}$ & $>600 \mathrm{~N}$ \\
Scale contact force & Zero & $<600 \mathrm{~N}$ & $600 \mathrm{~N}$ & $>600 \mathrm{~N}$ \\
Gravitational force & Zero & $<600 \mathrm{~N}$ & $600 \mathrm{~N}$ & $>600 \mathrm{~N}$ \\
\hline
\end{tabular}

The elevator accelerates gently downward (not falling).

Please circle one response in each row of the table to the right.

Draw a force diagram (of force(s) acting on you), and then explain your responses for scale contact force and gravitational force (in terms of physics concepts and principles).

Question 4 (5 points)

\begin{tabular}{lllll}
\hline Your mass & Zero & $<60 \mathrm{~kg}$ & $60 \mathrm{~kg}$ & $>60 \mathrm{~kg}$ \\
Your weight & Zero & $<600 \mathrm{~N}$ & $600 \mathrm{~N}$ & $>600 \mathrm{~N}$ \\
Scale contact force & Zero & $<600 \mathrm{~N}$ & $600 \mathrm{~N}$ & $>600 \mathrm{~N}$ \\
Gravitational force & Zero & $<600 \mathrm{~N}$ & $600 \mathrm{~N}$ & $>600 \mathrm{~N}$
\end{tabular}

The elevator cable suddenly breaks, and it falls freely.

Please circle one response in each row of the table to the right.

Draw a force diagram (of force(s) acting on you), and then explain your responses for scale contact force and gravitational force (in terms of physics concepts and principles).

\section{Question 5 (8 points)}

An object is suspended from a spring scale (its mass is $5 \mathrm{~kg}$.). That object is then immersed in water as shown on the right (Fig. 4), still suspended from the scale.

There is a gravitational force downward on the object by the Earth and a force by the spring scale i)

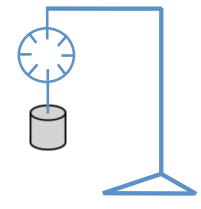

ii)

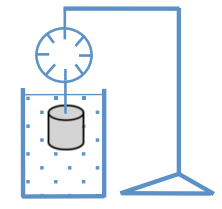

FIG. 4. An object suspended from a scale.

upward on the object, so that the scale indicates a force reading.

For each of the two situations, draw a force diagram:

Mass of object

$5 \mathrm{~kg}$

Weight of object

Scale contact force

Gravitational force

A) In the first case, what will be the value of weight, scale contact force, and gravitational force?

$$
\text { (Assume } a_{g}=10 \mathrm{~m} / \mathrm{s} \text { ) }
$$

(complete the table to the right...)

B) In the second case (object is suspended in water), will the mass, weight, scale contact force, gravitational force, and buoyancy force become zero, decrease, remain the same, or increase? (Please circle one response in each section of the table below.)

\begin{tabular}{lllll}
\hline Mass of object & Zero & Decrease & Same & Increase \\
Weight of object & Zero & Decrease & Same & Increase \\
Scale contact force & Zero & Decrease & Same & Increase \\
Gravitational force & Zero & Decrease & Same & Increase \\
Buoyancy force & Zero & Decrease & Same & Increase
\end{tabular}

Explain your interpretation of "weight" for your answer in the table above:

\section{Question 6 (5 points)}

Suppose you put an object on a scale on the ground (Fig. 5). The object has a certain mass, and there is a certain gravitational force exerted by the Earth. There is a contact force between the object and the scale, and you read a certain scale force.

If you take this scale and this object and set them on the surface of the moon (you're an astronaut!), will the mass, weight, scale contact force, and gravitational force become zero, decrease, remain the same, or increase?

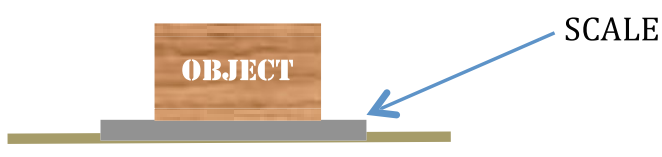

FIG. 5. An object on a scale on the ground. 
(Please circle one response in each row of the table below.)

\begin{tabular}{lllll}
\hline Mass of object & Zero & Decrease & Same & Increase \\
Weight of object & Zero & Decrease & Same & Increase \\
Scale contact force & Zero & Decrease & Same & Increase \\
Gravitational force & Zero & Decrease & Same & Increase
\end{tabular}

Draw a force diagram ([(of force(s) acting on the object]), and then explain your responses for scale contact force and gravitational force (in terms of physics concepts and principles).

Question 7 (18 pts.)

You are now "floating" around in the cabin of a spacecraft that is orbiting the Earth.

A) Circle either NO or YES to answer each question:

Is there gravitational force beyond Earth's $\quad$ NO YES atmosphere?

Is there gravitational force inside the spacecraft? NO YES

B) If there are any forces acting, circle each one in the right column below:

\begin{tabular}{ll}
\hline Forces acting upon the & - Contact force \\
spacecraft & - Gravitational force \\
& - Force in the direction of the \\
spacecraft'smotion (orbit) & - Contact force \\
Forces acting upon & - Gravitational force \\
you & - Force in the direction of \\
& your motion (orbit)
\end{tabular}

C) Explain how you and your spacecraft can remain in orbit around the Earth without burning any fuel:

D) Prior to the flight, you stood on a "bathroom scale" attached to the cabin floor and observed its reading. Now, with the spacecraft in orbit, you try to position your feet on the scale.

Circle the correct answer:

\begin{tabular}{ll}
\hline $\begin{array}{l}\text { What scale contact } \\
\text { force }\end{array}$ & - Zero \\
$\begin{array}{l}\text { (if any)will you } \\
\text { observe? }\end{array}$ & $\begin{array}{c}\text { Smaller than on Earth but not zero } \\
\text { flight }\end{array}$ \\
\hline
\end{tabular}

E) In this orbiting situation, are you and/or the spacecraft accelerating toward the Earth? Please explain:

Question 8 (no numerical grade)

People and books sometimes use the terms "free fall" and "weightless" to describe various situations. Please explain if (and how) these terms may or may not apply in the situations below (five situations were provided): (1) an apple dropping, (2) a ball moving towards a basket (parabolic motion), (3) a girl on her way up (after jumping on a trampoline), (4) the moon in orbit, and (5) some astronauts floating in a spaceship).

Question 9 (no numerical grade)

Please say what you understand by the following terms:

A) mass, B) weight, C) free fall, D) weightless (and/or weightlessness)

\section{APPENDIX B: PROTOCOL FOR STUDENT INTERVIEWS}

\section{WEIGHT, WEIGHTLESSNESS, AND FREE FALL}

1. A metal bar is suspended from a spring scale (demonstration). The same object is then submerged in water, still suspended from the scale. Explain whether or not the magnitudes of the gravitational force and scale forces will be equal. How about the scale contact force reading? How about mass? How about weight?

2. Some people define "weight" as the gravitational force on the object and others define it as the scale contact force (i.e., the scale reading). Under what situation would the two agree or disagree about the weight of the object?

3. Two astronauts, Hart and Phillip, in an Apollo spaceship had a heated debate about weightlessness. Hart contended that weightlessness is a reality while Phillip asserted that it is a misnomer and just a feeling not a reality. What might be the possible source (s) of their conflict?

4. In the light of such disagreements, what might be done about the ambiguous terms?

5. In what way, the scientific term "free fall" may pose difficulties in understanding the idea behind this term? And what might be done to avoid such difficulties?

INSTRUCTION

We discussed gravitational and scale forces in multiple situations. We also avoided terms "weight," "weightlessness," and "free fall" at the beginning of our learning. However, these terms were discussed later in our module and learning.

1. Explain whether and how the use of multiple situations (on moon, elevators, spaceships, etc.) helped you in understanding the physics behind weight, weightlessness, and free fall

2. Explain whether and how this approach helped you in understanding the terminological issues surrounding these terms.

3. In what way(s) has the learning of the terminology difficulties associated with the terms "weight," "weightlessness" and "free fall" been a good or worse experience to you.

4. What is your position regarding revealing language problems to your students? Would you do the same to your students? Explain.

5. What aspects of the module did you like, and what aspects did you dislike? 


\section{APPENDIX C: PROTOCOL FOR INSTRUCTOR INTERVIEWS}

1. Please explain your experiences of the instructional process, how did it go in trying to avoid the terms? Were students comfortable with not using weight, weightless, and free fall at the beginning? Was the subject appropriate for the students in terms of prior knowledge?

2. In what way (s) this approach might be better or worse than one of the traditional approaches to teach these concepts found in textbooks?
3. Do you have any preference on how to approach the teaching of weight? Do you prefer one of the definitions better than the other?

4. What is your position regarding revealing language problems to students?

5 . What parts of the module went well and what aspects did not go well?

6. What parts were difficult or easy for the students to understand?

7. Please share any general comments.
[1] R. Taibu, D. Rudge, and D. Schuster, Textbook presentations of weight: Conceptual difficulties and language ambiguities, Phys. Rev. ST Phys. Educ. Res. 11, 010117 (2015).

[2] R. B. Braithwaite, Lewis Carroll as Logician, Math. Gaz. 16, 174 (1932).

[3] A.B. Arons, Critical thinking and the baccalaureate curriculum, Liberal Educ. 71, 141 (1985).

[4] E. F. Mortimer and C. N. El-Hani, Conceptual Profiles: A Theory of Teaching and Learning Scientific Concepts (Springer Science \& Business Media, New York, 2014), Vol. 42.

[5] D. Clerk and M. Rutherford, Language as a confounding variable in the diagnosis of misconceptions, Int. J. Sci. Educ. 22, 703 (2000).

[6] H. T. Williams, Semantics in teaching introductory physics, Am. J. Phys. 67, 670 (1999).

[7] R. Taibu, Terms vs. Concepts-The Case of Weight, Phys. Teach. 55, 34 (2017).

[8] I. Galili, Interpretation of students' understanding of the concept of weightlessness, Res. Sci. Educ. 25, 51 (1995).

[9] H. Stein, I. Galili, and Y. Schur, Teaching a new conceptual framework of weight and gravitation in middle school, J. Res. Sci. Teach. 52, 1234 (2015).

[10] F. W. Sears, Weight and Weightlessness, Phys. Teach. 1, 20 (1963).

[11] A. DiSessa, Toward an epistemology of physics, Cognit. Instr. 10, 105 (1993).

[12] Z. Gurel and H. Acar, Research into students' views about basic physics principles in a weightless environment, Astron. Educ. Rev. 2, 65 (2003).

[13] D. Chandler, Weightlessness and microgravity, Phys. Teach. 29, 312 (1991).

[14] R. Taibu, A Study of Conceptual and Language Issues Surrounding Weight, Weightlessness, and Free Fall: Textbook Analysis, Instructional Design, and Assessment (2015), Dissertation, 596, http://scholarworks.wmich.edu/ dissertations/596.

[15] R. D. Knight, Physics for Scientists and Engineers: A Strategic Approach, 3rd ed. (Pearson Education, Inc, Boston, 2013).
[16] T.S. Kuhn, The Structure of Scientific Revolutions (University of Chicago Press, Chicago, 1962).

[17] D. Heywood and J. Parker, The Pedagogy of Physical Science (Springer, London, 2010).

[18] J. S. Touger, When words fail, Phys. Teach. 29, 90 (1991).

[19] R. F. Bornstein, S. C. Rossner, E. L. Hill, and M. L. Stepanian, Face validity and fakability of objective and projective measures of dependency, Journal of Personality Assessment 63, 363 (1994).

[20] B. Johnson and L. Christensen, Educational Research, Quantitative, Qualitative, and Mixed Approaches, 3rd ed. (Sage Publications, Los Angeles, 2008).

[21] R. Karplus, Educational aspects of the structure of physics, Educ. Asp. Struct. Phys. 49, 238 (1981).

[22] J. Lee Rodgers and W. A. Nicewander, Thirteen ways to look at the correlation coefficient, Am. Stat. 42, 59 (1988).

[23] R. D. Wimmer and J. R. Dominick, Mass Media Research: An Introduction, 5th ed. (Wadsworth, Belmont, CA, 1994).

[24] T. M. Andrews, M. J. Leonard, C. A. Colgrove, and S. T. Kalinowski, Active learning not associated with student learning in a random sample of college biology courses, CBE-Life Sci. Educ. 10, 394 (2011).

[25] R. R. Hake, Interactive-engagement versus traditional methods: A six-thousand-student survey of mechanics test data for introductory physics courses, Am. J. Phys. 66, 64 (1998).

[26] J. R. Fraenkel and N.E. Wallen, How to Design and Evaluate Research in Education, 7th ed (McGraw-Hill, Boston, 2009).

[27] J. C. Hattie, Visible Learning: A Synthesis of Over 800 Meta-Analyses Relating to Achievement (Routledge, Taylor \& Francis Group, London, New York, 2009).

[28] R. J. Osborne and J. K. Gilbert, A technique for exploring students' views of the world, Phys. Educ. 15, 376 (1980).

[29] J. W. Creswell, Qualitative Inquiry \& Research Design: Choosing among Five Approaches, 2nd ed. (Sage Publications, Inc., Thousand Oaks, CA, 2007).

[30] J. W. Creswell, Educational Research: Planning, Conducting, and Evaluating Quantitative and Qualitative Research (Pearson Education, Inc., Upper Saddle River, New Jersey, 2002). 
[31] R. L. Kahn and C. F. Cannell, The Dynamics of Interviewing (John Wiley, New York, 1957).

[32] C. Marshall and G. B. Rossman, Designing Qualitative Research, 5th ed. (Sage Publications, Inc, Thousand Oaks, CA, 2011).

[33] C. Marshall and G. B. Rossman, Designing Qualitative Research, 4th ed. (SAGE Publications, Thousand Oaks, 2006).

[34] P. L. Brown, S. K. Abell, A. Demir, and F. J. Schmidt, College science teachers' views of classroom inquiry, Sci. Educ. 90, 784 (2006).

[35] J. Cohen, Statistical Power Analysis for the Behavioral Sciences, 2nd ed. (Erlbaum, Hillsdale, NJ, 1988).

[36] I. Galili, Weight and gravity: Teachers' ambiguity and students' confusion about the concepts, Int. J. Sci. Educ. 15, 149 (1993).

[37] H. Stein and I. Galili, and Y. Schur, Distinguishing between weight and gravitational force in thinking journey mode of teaching science, Eur. Sc. Educ. Res. Assoc. Istanbul, Turkey
[38] J. W. Creswell and V.L.P. Clark, Designing and Conducting Mixed Methods Research (Sage, Thousand Oaks, CA, 2007).

[39] I. Galili and Y. Lehavi, The importance of weightlessness and tides in teaching gravitation, Am. J. Phys. 71, 1127 (2003).

[40] D. Heywood and J. Parker, Describing the cognitive landscape in learning and teaching about forces, Int. J. Sci. Educ. 23, 1177 (2001).

[41] I. Galili and V. Bar, Children's operational knowledge about weight, Int. J. Sci. Educ. 19, 317 (1997).

[42] I. Galili and D. Kaplan, Students' operation with the concept of weight, Sci. Educ. 80, 457 (1996).

[43] G. Tural, A. Akdeniz, and N. Alev, Effect of 5E Teaching Model on Student Teachers' Understanding of Weightlessness, J. Sci. Educ. Technol. 19, 470 (2010).

[44] J. Parker and D. Heywood, Exploring the relationship between subject knowledge and pedagogic content knowledge in primary teachers' learning about forces, J. Sci. Educ. Technol. 22, 89 (2000). 